\title{
Online Two-Section PV Array Fault Diagnosis with Optimized Voltage Sensor Locations
}

\author{
Yihua Hu, Member, IEEE, Jiangfeng Zhang, Wenping Cao, Senior Member, IEEE, Jiande Wu, Member, IEEE, \\ Gui Yun Tian, Senior Member, IEEE, Stephen J. Finney, James L. Kirtley, Life Fellow, IEEE
}

\begin{abstract}
Photovoltaic (PV) stations have been built widely in the world to utilize solar energy directly. In order to reduce the capital and operational costs, early fault diagnosis is playing an increasingly important role by enabling the long effective operation of $\mathrm{PV}$ arrays. This paper analyzes the terminal characteristics of faulty PV strings and arrays, and develops a PV array fault diagnosis technique. The terminal current-voltage curve of a faulty PV array is divided into two sections: a highvoltage and a low-voltage fault diagnosis section. The corresponding working points of healthy string modules, healthy and faulty modules in an unhealthy string are then analyzed for each section. By probing into different working points, a faulty PV module can be located. The fault information is of critical importance for the maximum power point tracking (MPPT) and the array dynamical reconfiguration. Furthermore, the string current sensors can be eliminated while the number of voltage sensors can also be reduced by optimizing voltage sensor locations. Typical fault scenarios including mono-string, multi-string and partial shadow for a $1.6 \mathrm{~kW} 3 \times 3 \mathrm{PV}$ array are presented and experimentally tested to confirm the effectiveness of the proposed fault diagnosis method.
\end{abstract}

Index Terms-Fault diagnosis, optimization, photovoltaics, terminal characteristics, voltage sensors.

\section{INTRODUCTION}

$\mathrm{P}$ HOTOVOLTAIC (PV) systems provide a promising solution to directly utilizing solar energy and are currently gaining in popularity as the technologies are mature and the material costs are driven down [1]-[5]. However, as they are installed in outdoor environments, operational and maintenance costs have always been an issue, demanding some fault diagnosis functions to improve system reliability.

A PV module consists of dozens of PV cells in series connections. A large number of PV modules connected in series form a PV string, which can be further connected in parallel to form a PV array. PV modules are characterized with low power density and low output voltage [6]-[8]. If the PV system is connected to a power grid, a large number of PV modules are needed to connect in series to achieve a high voltage level. Typically, a $400 \mathrm{~V}$ bus voltage is required for a $220 \mathrm{~V} 50 \mathrm{~Hz}$ single-phase grid, and a $600 \mathrm{~V}$ bus voltage for a three-phase grid. Similarly, a large number of PV strings are also needed to connect in parallel to increase their power level [9],[10]. For

Manuscript received October 30, 2014; revised January 24, 2015; April 18 , 2015 and May 23, 2015; accepted June 7, 2015.

Copyright (c) 2015 IEEE. Personal use of this material is permitted. However, permission to use this material for any other purposes must be obtained from the IEEE by sending a request to pubs-permissions@ieee.org.

Y. Hu, J. Zhang and S. Finney are with the Department of Electronic \& Electrical Engineering, University of Strathclyde, Glasgow, G1 1XQ, U.K. example, a $20 \mathrm{~kW}$ grid-connected PV system generally employs 80 modules to form a $20 \times 4$ array (i.e. 20 modules in a string and 4 strings to form an array).

In field conditions, a number of factors can cause the PV array to reduce its output power. In this paper, any cause for this reduction is considered as the "fault". It can be permanent (such as open-circuits, short-circuits and device aging), or temporary (such as dust, leave, bird dropping and shadow). A temporary fault can be cleared after a short period of time while a permanent fault would persist over time. Temporary faults can normally be identified by human eyes and thus be cleared through maintenance. Some permanent faults can be seen if the damage is severe while other permanent faults are invisible to the naked eye so that they may propagate and cause the PV modules to deteriorate over time. PV faults can occur in the PV array and generate different effects on the performance and lifetime of the PV system [11]-[16]. Currently, thermal cameras [17]-[23], earth capacitance measurements (ECM) [24] and time domain reflectomery (TDR) [25] are the three popular methods for PV fault diagnosis. Thermal cameras can be employed to detect the temperature characteristics of a PV array under fault conditions. Thermal images can also be linked to the maximum power point tracking (MPPT) algorithm of the PV controller [22]. In practice, a gradual change in the thermal image of the PV module (e.g. due to device aging) poses a technical challenge [23], and high system costs also limit the wide application of thermal cameras. The ECM can locate the disconnection of PV strings while the TDR technology can predict the degradation of the PV array. Nonetheless, both ECM and TDR can only operate offline [24],[25]. In practice, online diagnosis methods are highly desired, which can take measurements while the tested device is in operation. To improve this, an automatic supervision and fault detection is proposed in [26],[27] based on power loss analysis. However, it requires surrounding environmental information and cannot identify the faulty module. An operating voltage-window is then developed based on the PV string operation voltage and ambient temperature [28]. It can locate the open and short faults but still cannot identify the faulty module from the array. Currently, both offline and online fault diagnosis methods have been developed. Offline diagnosis methods cannot give realtime fault information that is the key factor for PV array optimization operation under fault condition. Current, online

W. Cao and J. L. Kirtley are with the Department of Electrical Engineering and Computer Science, Massachusetts Institute of Technology, Cambridge, MA, 02139, U.S.A.

$\mathrm{J}$. Wu is with the College of Electrical Engineering, Zhejiang University, Hangzhou, 310027, P. R. China.

G. Tian is with the School of Electrical and Electronic Engineering, Newcastle University, Newcastle upon Type, NE1 7RU, U.K. 
fault diagnosis methods suffer from high costs or incapability of locating fault modules. A model-based reconfiguration algorithm is developed in [29] to realize the fault-tolerant operation. But it needs a large number of electrical relays to reconfigure PV arrays. A similar technology, the in-situ rearrangement strategy, can decrease the influence of shadow [30]-[33]. However, its success depends on three conditions: i) a large number of relays are used. ii) the health state of all PV modules should be monitored. iii) high computing resource of the controller is required to calculate complex optimal arrangements. These increase the system cost and control complexity. Paper [34] develops an improved strategy which combines power channels and relays to combat the shadow influence but it also needs the healthy state of PV modules. Paper [35] proposes a fingerprint curve of the PV array under shading conditions to find the key information (e.g. open-circuit and short-circuit points and MPP region) but it cannot locate the faulted modules. Paper [36] presents a fault diagnosis technique using current and voltage sensors but the system cost is quite high. Paper [22] presents a method to use the fault diagnosis information for global MPPT without a need to trace I-V curves. It becomes clear that online fault diagnosis is important because i) it is the prerequisite for any array dynamical reconfiguration. ii) it can provide crucial information for global MPPT; (iii) it contains key state-of-health information useful for system maintenance.

This paper proposes a low cost and online fault diagnosis method with optimized voltage sensor locations that can effectively locate the faulty PV strings and faulty modules. The paper is organized as follows. Section II introduces PV fault mechanisms. Section III illustrates the optimization of sensor locations. Section IV describes the two-section PV array fault diagnosis method. Section V presents experimental results to verify the proposed method, followed by a short conclusion in Section VI.

\section{FAULT MECHANISMS}

Firstly, it is crucial to understand fault mechanisms prior to developing fault diagnosis techniques.

\section{A. PV string faults}

The PV string is the basic structure of a PV array. Fig. 1 presents typical output characteristics of the PV string under faulty conditions; the PV module parameters are listed in Table I. The string includes three modules with non-uniform illumination, the corresponding environment parameters are $850 \mathrm{~W} / \mathrm{m}^{2}, 25^{\circ} \mathrm{C} ; 620 \mathrm{~W} / \mathrm{m}^{2}, 25^{\circ} \mathrm{C} ; 400 \mathrm{~W} / \mathrm{m}^{2}, 25^{\circ} \mathrm{C}$. Each module has uniform illumination. It can be found that: i) The multi-stage characteristics are caused by the differing output current of each module; ii) In the low voltage diagnosis section, the faulty modules are short-circuited, and the terminal voltage of the corresponding faulty module is zero.

In order to restrict the hot-spots in a PV module, a bypass diode is connected in parallel to PV cells. The corresponding structure is named the cell-unit, which is composed of $m$ PV cells. The PV module is connected in series by $n$ cell units to achieve the high output voltage. Usually, partial shadow is also accrued in one PV module. Due to the cell-unit structure, even though only one cell is faulty $\left(0 \mathrm{~W} / \mathrm{m}^{2}\right)$, the output power of the cell-unit will decrease dramatically. Fig. 2(a) presents experimental results of the faulty cell-unit that includes $24 \mathrm{PV}$ cells with one faulty PV cell; the experimental environment parameters are $790 \mathrm{~W} / \mathrm{m}^{2}$ at $24^{\circ} \mathrm{C}$. The faulty cell is equivalent to a resistance. As the current increases, the corresponding cellunit output power is decreased dramatically. For instance, the faulty cell-unit works at $0.96 \mathrm{~A}$, and its output power is $4.75 \mathrm{~W}$ (about $10 \%$ of the output at healthy condition) and this power reduces to nearly zero when the cell-unit current is higher than $1 \mathrm{~A}$. In order to achieve a global MPP for the PV array, the current is much higher than 1 A under the condition in Fig. 2. Therefore, the output voltage for a faulty cell-unit is effectively negligible, as shown in Fig. 2.

Therefore, when a PV module is subjected to partial shading, its terminal output voltage is lower than the healthy module but higher than zero. In Fig. 2(b), the PV module loses one of the cell-units and its output voltage is reduced to $\frac{n-1}{n}$ of the output voltage.

PV string fault diagnosis can be achieved by measuring the PV module voltage, which changes with the string working point. When the string works in the low voltage diagnosis section, the faulty module can be located because its output voltage is zero (full shadow) or lower than the healthy module (partial shadow).

\section{B. $P V$ array faults}

When a PV array is faulted, the faulty module has a lower effective illumination than healthy modules. Take a $3 \times 3$ array for example. Fig. 3(a) shows a multi-string faulty condition and Fig. 3(b) shows its I-V characteristics. In Fig. 3(a), the diodes are used to block the reverse current when a fault occurs. The output I-V characteristics can be divided into two sections: a high voltage diagnosis section and a low voltage diagnosis section (constant output current). In the latter section, the faulty module in the faulty string is shorted by bypass diodes where both healthy string and unhealthy string carry the same current. PV string current sensors cannot distinguish the unhealthy string from healthy strings. Nevertheless, the healthy modules in the faulty string have a higher output voltage than the modules in the healthy string, as points $\mathrm{A}_{1}$ and $\mathrm{A}_{2}$ illustrated in Fig. 3(c). The voltage difference between the healthy module in the unhealthy string, and the module in the healthy string can be employed to locate the faulty module.

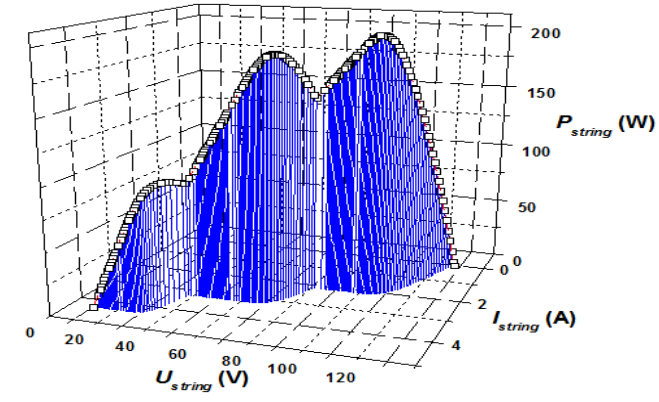

Fig. 1 Output characteristics of the faulty string.

TABLE I SPECIFICATIONS OF THE PV MODULE

\begin{tabular}{lc}
\hline \multicolumn{1}{c}{ Parameter } & Value \\
\hline Open-circuit voltage & $44.8 \mathrm{~V}$ \\
Short-circuit current & $5.29 \mathrm{~A}$ \\
Power output & $180 \mathrm{~W}$ \\
MPP current & $5 \mathrm{~A}$ \\
MPP voltage & $36 \mathrm{~V}$ \\
Current temperature coefficient & $0.037 \% / \mathrm{K}$ \\
Voltage temperature coefficient & $-0.34 \% / \mathrm{K}$
\end{tabular}




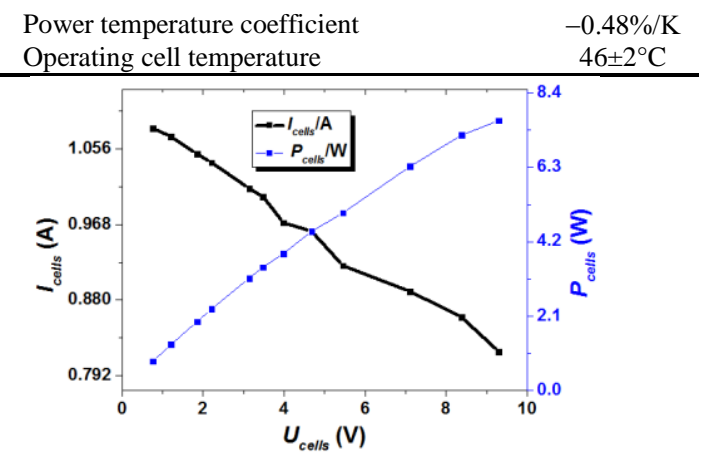

(a)

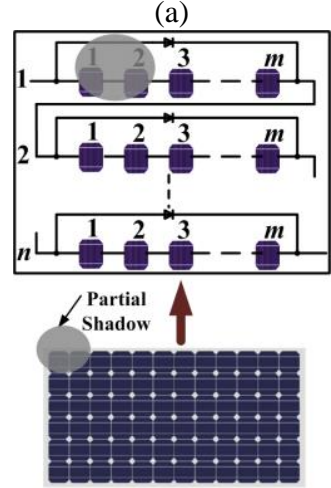

(b)

Fig. 2 PV string under partial shading conditions. (a) The PV cell-unit output. (b) Partial shading illustration.

In this paper, $s$ modules are connected in series to form a PV string and $p$ PV strings are connected in parallel to form a PV array. For a $p$ row $s$ column array, assume that there are $x$ faulted modules in the unhealthy string. In Fig. 3(c), $U_{A l}$ is the voltage of a PV module in a healthy string, such as PV11; $U_{A 2}$ is the voltage of a healthy PV module in an unhealthy string, such as PV22. $U_{A I}$ and $U_{A 2}$ can be expressed as:

$$
\begin{gathered}
U_{A 1}=\frac{U_{\text {array }}}{s} \\
U_{A 2}=\frac{U_{\text {array }}}{s-x}
\end{gathered}
$$

where $U_{\text {array }}$ is the output voltage of PV arrays.

The high voltage diagnosis section in Fig. 3(b) is due to a lower solar illumination of the faulty module. The output current of the unhealthy string is limited by the faulty module output current. Therefore, the unhealthy string output current is lower than the healthy string. Since all the modules contribute to electricity generation, there are three working points in two output characteristics. $\mathrm{A}_{3}$ is the working point of modules in the healthy string; $\mathrm{A}_{4}$ is working point of the faulty modules in the unhealthy string; $A_{5}$ is the working point of normal modules in the unhealthy string; as in Fig. 3(d). Because both $A_{3}$ and $A_{5}$ are the working points of a healthy module, they share the same output curve characteristics. Because $\mathrm{A}_{4}$ and $\mathrm{A}_{5}$ are the working points of an unhealthy module and a healthy module in the same string, they have the same output current.

Voltages $U_{A 3}, U_{A 4}$ and $U_{A 5}$ for working points $\mathrm{A}_{3}, \mathrm{~A}_{4}$ and $\mathrm{A}_{5}$ are given by:

$$
U_{A 3} \cdot s=U_{A 4} \cdot x+U_{A 5} \cdot(s-x)
$$

According to the previous analysis, $U_{A 4}<U_{A 3}<U_{A 5}$. This can be employed to locate faulty modules without current information.

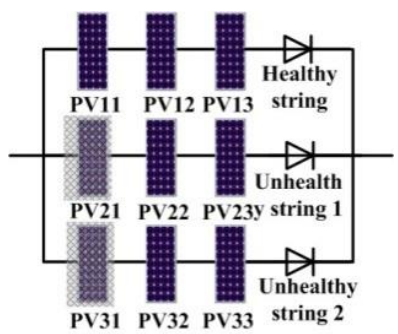

(a)

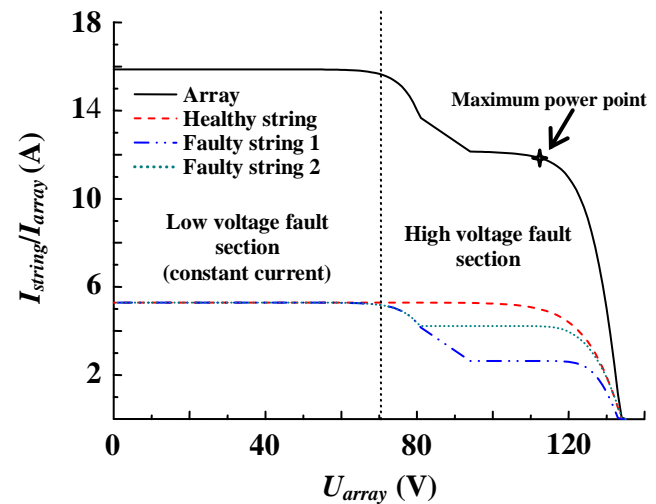

(b)

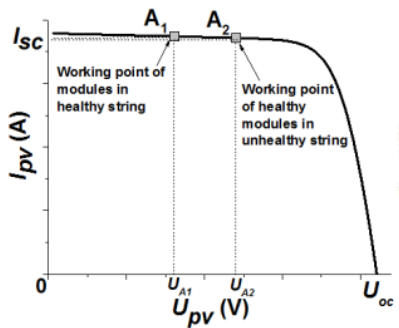

(c)

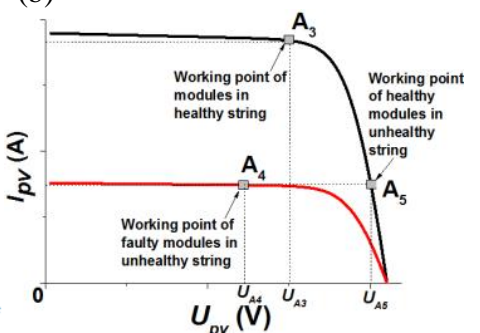

(d)
Fig. 3 PV array under fault conditions. (a) Faulty $3 \times 3$ PV array. (b) Output characteristics. (c) Working points in the voltage fault diagnosis section. (d) Working points in the high-voltage section.

The extreme condition for the PV array under non-uniform illumination is that the illumination on the faulty module is zero. Fig. 4 presents the output curves of healthy string and unhealthy string under this condition. There is a zero-output condition, where the faulty string does not generate electricity. When the array output voltage is between $100 \sim 130 \mathrm{~V}$, every module in the healthy string generates electricity and works in the highvoltage diagnosis section. In the unhealthy string, the faulty module cannot generate electricity. Although the healthy modules work in the high-voltage diagnosis section, the unhealthy string still cannot reach the PV array voltage. Therefore the healthy modules in the unhealthy string are effectively open-circuited, similar to the faulted modules. There is neither current flowing in the unhealthy string, nor in the bypass diodes. That is, all the modules in an unhealthy string are open-circuited.

Therefore, the fault diagnosis can be achieved by analyzing the module voltage at different diagnosis sections. This also removes the necessity of current sensors. In this work, the twostage power conversion [37] is adopted so that the control of the PV system is load independent. That is, the PV's working point can be chosen at will in the two-stage PV system where the 
front-end DC-DC converter tracks the

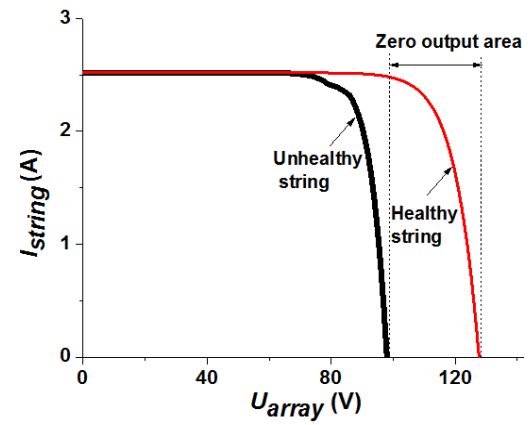

Fig. 4 Extreme case of the PV array fault.

desired working point of the PV array; the bus voltage control and the DC-AC inverter control ensure that the grid current is controlled as per the input power.

\section{OPTIMIZATION OF SENSOR LOCATIONS}

In order to achieve the PV array fault diagnosis, the reading of PV module voltage is needed. Due to the large number of PV modules employed, a large number of voltage sensors are also needed in the first instance.

\section{A. Sensor placement strategy}

There are three basic sensor placement methods, as shown in Fig. 5. If every module's terminal voltage is measured by a voltage sensor by method 1; and the total number of sensors is $p \times s$. In method 2 , each voltage sensor measures the voltage between two nodes in the same column of adjacent strings; and $(p-1) \times(s-1)$ voltage sensors are needed. In method 3 , the electric potential difference of adjacent modules is measured; the corresponding number of sensors is $p \times(s-2)$. The large number of voltage sensors may increase system capital cost and information processing burden. Therefore, the voltage placement method needs to be optimized.

Fig. 6 shows an equivalent PV matrix where a PV module is shown as a dot; the connection line of the adjacent module is represented by a node. The proposed voltage placement strategy is developed by the following steps:

i) All the nodes should be covered by voltage sensors.

ii) A sensor can only connect one node in a string.

iii) Voltage sensor nodes cover different isoelectric points from different strings.

iv) If $p$ or $s$ is an even number, each node is connected to and only to one sensor. If both $p$ and $s$ are odd, there is one and only one node to be connected to two different sensors, while each of remaining nodes is connected to one sensor.

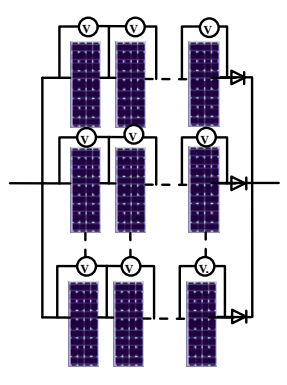

(a)

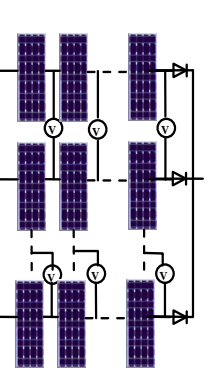

(b)

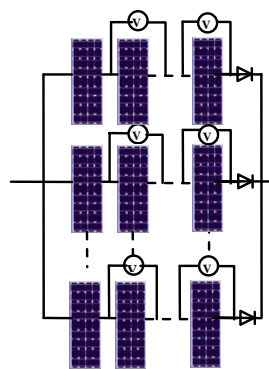

(c)
Fig. 5 Voltage sensor placement methods: (a) 1, (b) 2, (c) 3.

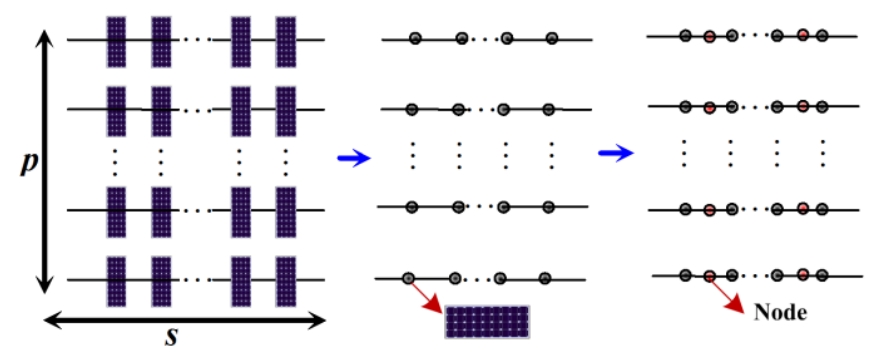

Fig. 6 Equivalent matrix.

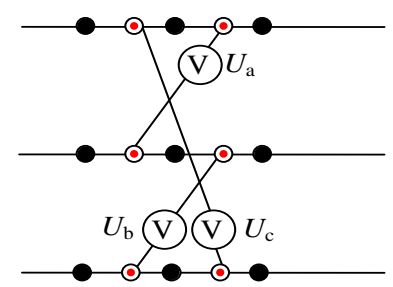

Fig. 7 Simplified voltage sensor placement for a $3 \times 3$ PV array.

TABLE II NUMBER OF VOLTAGE SENSORS USED BY DIFFERENT METHODS

\begin{tabular}{ccccc}
\hline Method & 1 & 2 & 3 & Proposed \\
\hline No. & $p \times s$ & $(p-1) \times(s-1)$ & $p \times(s-2)$ & $p \times(s-1) / 2$ \\
\hline
\end{tabular}

Fig. 7 presents an example of the $3 \times 3$ PV array. According to the proposed sensor placement strategy, only three voltage sensors are needed.

The minimum number of sensors used to detect all possible faults should be $\lceil p \times(s-1) / 2\rceil$. When a node is not connected to any sensor, the two adjacent PV modules of this node cannot be discriminated once a fault occurs at one of the two modules. The total number of nodes is equal to $\lceil p \times(s-1) / 2\rceil$. This is summarized in Table II. Clearly, the proposed method uses less voltage sensors than other three methods.

\section{B. Mathematical model of the proposed strategy}

The variable $a_{i j}$ is defined as the state of the PV module sitting at the $i$-th string and $j$-th module (i.e. $(i, j))$ in the $p \times s$ array. If this module is healthy, $a_{i j}=1$, otherwise $a_{i j}=0$. The terminal voltage of the $(i, j)$ module is denoted by $u_{i j}$, and the reading of a voltage sensor connecting the $(i, j)$ and $(r, k)$ modules is denoted by $R_{i, j, r, k}$. Consider that each string has at least one healthy module. The number of healthy modules in the $i$-th string equalizes $a_{i 1}+a_{i 2}+\cdots+a_{i s}$. The terminal voltage $u_{i j}$ of the $(i, j)$ module is equal to a fraction of $U_{\text {array }}$, and this fraction is 0 if $a_{i j}=0$, and is $1 /\left(a_{i 1}+a_{i 2}+\cdots+\right.$ $\left.a_{i s}\right)$ if $a_{i j}=1$. That is,

$$
u_{i j}=\frac{a_{i j U_{\text {array }}}}{a_{i 1}+a_{i 2}+\cdots+a_{i s}}
$$

Note that the total output voltage of the modules $(i, 1),(i$, $2), \ldots$, and $(i, j)$ is the sum of the terminal voltage of $j$ modules, i.e., $u_{i 1}+u_{i 2}+\cdots+u_{i j}$. Similarly the total output voltage of the modules $(r, 1),(r, 2), \ldots$, and $(r, k)$ equalizes $u_{r 1}+u_{r 2}+$ $\cdots u_{r k}$. Therefore, the reading of the voltage sensor connecting the $(i, j)$ module and the $(r, k)$ module is calculated as

$$
\begin{gathered}
R_{i, j, r, k}=\left(u_{i 1}+u_{i 2}+\cdots+u_{i j}\right)-\left(u_{r 1}+u_{r 2}+\cdots u_{r k}\right) \\
=\frac{\left(a_{i 1}+a_{i 2}+\cdots+a_{i j}\right) U_{\text {array }}}{a_{i 1}+a_{i 2}+\cdots+a_{i s}}-\frac{\left(a_{r 1}+a_{r 2}+\cdots+a_{r k}\right) U_{\text {array }}}{a_{r 1}+a_{r 2}+\cdots+a_{r s}}
\end{gathered}
$$


When the working point of a PV string moves to the high voltage section, the output voltage of the healthy modules increases until reaching $U_{o c}$. The faulted modules in the string will equally divide the remaining voltage $U_{\text {array }}-\left(a_{i 1}+a_{i 2}+\right.$ $\left.\cdots+a_{i s}\right) U_{o c}$. The following relations hold for a string including both healthy and unhealthy modules.

$$
\begin{gathered}
u_{i j}=a_{i j} U_{o c}+\frac{\left(1-a_{i j}\right)\left(U_{\text {array }}-\left(a_{i 1}+a_{i 2}+\cdots+a_{i s}\right) U_{o c}\right)}{s-\left(a_{i 1}+a_{i 2}+\cdots+a_{i s}\right)} \\
=\frac{\left(a_{i j} s-\left(a_{i 1}+a_{i 2}+\cdots+a_{i s}\right)\right) U_{o c}}{s-\left(a_{i 1}+a_{i 2}+\cdots+a_{i s}\right)}+\frac{\left(1-a_{i j}\right) U_{\text {array }}}{s-\left(a_{i 1}+a_{i 2}+\cdots+a_{i s}\right)} \\
R_{i, j, r, k}=\left(u_{i 1}+u_{i 2}+\cdots+u_{i j}\right)-\left(u_{r 1}+u_{r 2}+\cdots u_{r k}\right) \\
=\frac{\left(s \sum_{l=1}^{j} a_{i l}-j \sum_{l=1}^{s} a_{i l}\right) U_{o c}}{s-\sum_{l=1}^{s} a_{i l}}+\frac{\left(j-\sum_{l=1}^{j} a_{i l}\right) U_{\text {array }}}{\sum_{l=1}^{s} a_{i l}} \\
-\frac{\left(s \sum_{l=1}^{k} a_{r l}-k \sum_{l=1}^{s} a_{r l}\right) U_{o c}}{s-\sum_{l=1}^{s} a_{r l}}-\frac{\left(k-\sum_{l=1}^{k} a_{r l}\right) U_{\text {array }}}{\sum_{l=1}^{s} a_{r l}}
\end{gathered}
$$

The reading $R_{i, j, r, k}$ at the high voltage section provides extra equations to solve variable $a_{i j}$. There is a way to design the optimal sensor placement for any $p \times s$ array with $\lceil p \times(s-1) / 2\rceil$ sensors. If $p$ is an even number, the $p \times s$ array can be divided into $\frac{p}{2}$ elements of $2 \times s$ arrays. For each $2 \times s$ array, it needs to apply the optimal sensor placement method by using $\frac{p}{2} \times s$ sensors. If $p$ is odd, the $p \times s$ array consists of one $3 \times s$ array and $\frac{p-3}{2}$ elements of $2 \times s$ arrays. It needs to apply the sensor placement method for these elements and the number of sensors needed is equal to $\lceil 3 \times(s-1) / 2\rceil+$ $\frac{p-3}{2}(s-1)$. By considering both even and odd numbers,

$$
\lceil 3 \times(s-1) / 2\rceil+\frac{p-3}{2}(s-1)=\lceil p \times(s-1) / 2\rceil
$$

Therefore, the optimal number of sensors can be obtained.

\section{Two-SECTION PV ARRAY FAUlt DiagnOSIS STRATEGY}

The proposed PV array fault diagnosis strategy is implemented in three steps: locating healthy PV string, locating faulty module in the low-voltage diagnosis section, and in the high-voltage diagnosis section.

\section{A. Locating healthy PV strings}

The information of healthy strings is useful to identify a faulty module. Thus the first step in fault diagnosis is to locate healthy PV strings. Because of the absence of current sensors in the string, the healthy string cannot be found directly. When a PV array changes from a healthy condition to an unhealthy condition, the voltage sensor can pick up the change.

i) If the voltage sensor reading $R_{i, j, r, k}$ always satisfies $R_{i, j, r, k}=\frac{j-k}{s} U_{\text {array }}$ despite any changes of the working point along the I-V curve, both $i$-th and $r$-th strings are healthy.

ii) If the $i$-th string is healthy, the sensor reading $R_{i, j, r, k}$ satisfies $\frac{R_{i, j, r, k}}{U_{\text {array }}}-\frac{j}{s}=-\frac{a_{r 1}+a_{r 2}+\cdots+a_{r k}}{a_{r 1}+a_{r 2}+\cdots+a_{r s}}$ at low voltage working points. This can be used to judge the number of faulty modules in the $r$-th string.

iii) If the $i$-th string is healthy, and $\left(R_{i, j, r, k}-\frac{j}{s} U_{\text {array }}\right)$ remains constant for all working points, there is no current flowing in the $r$-th string, i.e., the $r$-th string is open circuited. This is because that $\left(R_{i, j, r, k}-\frac{j}{s} U_{\text {array }}\right)$ is equal to the voltage of the first $k$ modules in the $r$-th string (i.e. $u_{r 1}+u_{r 2}+$ $\left.\cdots u_{r k}\right)$. Whenever there is current flowing in the $r$-th string, there will be at least one module works at low voltage working points (e.g., $U_{\text {array }}<U_{o c}$ ). At the low voltage section, the reading of $u_{r 1}+u_{r 2}+\cdots u_{r k}$ is a function of $U_{\text {array }}$ and cannot remain constant.

\section{B. Locating faulty PV modules in the low-voltage section}

After locating the healthy string, the next step is to find the faulty PV module. In the low voltage diagnosis section, the faulty modules are shorted. The corresponding fault diagnosis eigenvalue of the mono-string faulty is presented in Table III, where the fully-faulty module indicates that all cell-units in the module are faulty (0: healthy and 1: faulty). No. 7 (111) is the extreme case that all the modules in this string are faulty. Even though the PV array works in the low-voltage diagnosis section, the modules are open-circuited when all modules are faulty. Table IV shows the multi-string eigenvalues. From these, the faulty module can be identified easily.

\section{TABLE III VOLTAGE OF THE MONO-STRING ALL FAULTED MODULES}

\begin{tabular}{cccc}
\hline $\mathrm{PV}_{31} \sim \mathrm{PV}_{33}$ & $U_{\mathrm{a}}$ & $U_{\mathrm{b}}$ & $U_{\mathrm{c}}$ \\
\hline 100 & $U_{\text {array }} / 3$ & $2 U_{\text {array }} / 3$ & $U_{\text {array }} / 6$ \\
010 & $U_{\text {array }} / 3$ & $U_{\text {array }} / 6$ & $U_{\text {array }} / 6$ \\
001 & $U_{\text {array }} / 3$ & $U_{\text {array }} / 6$ & $2 U_{\text {array }} / 3$ \\
110 & $U_{\text {array }} / 3$ & $2 U_{\text {array }} / 3$ & $\square U_{\text {array }} / 3$ \\
011 & $U_{\text {array }} / 3$ & $\square U_{\text {array }} / 3$ & $2 U_{\text {array }} / 3$ \\
101 & $U_{\text {array }} / 3$ & $2 U_{\text {array }} / 3$ & $2 U_{\text {array }} / 3$ \\
111 & $U_{\text {array }} / 3$ & $2 U_{\text {array }} / 3-U_{\text {oc }}$ & $2 U_{\text {oc }}-U_{\text {array }} / 3$ \\
000 & $U_{\text {array }} / 3$ & $U_{\text {array }} / 3$ & $U_{\text {array }} / 3$ \\
\hline
\end{tabular}

TABLE IV VOLTAGE OF THE MULTI-STRINGS FULLY FAULTED MODULES

\begin{tabular}{cccc}
\hline $\mathrm{PV}_{11} \sim \mathrm{PV}_{13} / \mathrm{PV}_{21} \sim \mathrm{PV}_{23}$ & $U_{\mathrm{a}}$ & $U_{\mathrm{b}}$ & $U_{\mathrm{c}}$ \\
\hline $100 / 100$ & $U_{\text {array }} / 2$ & $U_{\text {array }} / 6$ & $2 U_{\text {array }} / 3$ \\
$010 / 100$ & $U_{\text {array }} / 2$ & $U_{\text {array }} / 6$ & $U_{\text {array }} / 6$ \\
$001 / 100$ & $U_{\text {array }}$ & $U_{\text {array }} / 6$ & $U_{\text {array }} / 6$ \\
$100 / 010$ & $U_{\text {array }} / 6$ & $U_{\text {array }} / 6$ & $2 U_{\text {array }} / 3$ \\
$010 / 010$ & $U_{\text {array }} / 6$ & $U_{\text {array }} / 6$ & $U_{\text {array }} / 6$ \\
$001 / 010$ & $U_{\text {array }} / 2$ & $U_{\text {array }} / 6$ & $U_{\text {array }} / 6$ \\
$100 / 001$ & 0 & $2 U_{\text {array }} / 3$ & $2 U_{\text {array }} / 3$ \\
$010 / 001$ & 0 & $2 U_{\text {array }} / 3$ & $U_{\text {array }} / 6$ \\
$001 / 001$ & $U_{\text {array }} / 2$ & $2 U_{\text {array }} / 3$ & $U_{\text {array }} / 6$ \\
$110 / 100$ & 0 & $U_{\text {array }} / 6$ & $2 U_{\text {array }} / 3$ \\
$101 / 100$ & $U_{\text {array }}$ & $U_{\text {array }} / 6$ & $2 U_{\text {array }} / 3$ \\
$011 / 100$ & $U_{\text {array }}$ & $U_{\text {array }} / 6$ & $\square U_{\text {array }} / 3$ \\
\hline
\end{tabular}

In practice, partial shading is a very common fault [2][3][5][12]-[14][22]-[33]. This is illustrated in detail in Table V. Both Tables III and V are concerned with PV module faults. Tables III deals with the fully-faulted module where all cellunits are faulted while Table V shows a partially faulted module including some faulted cell-units. Their output voltages are zero and non-zero, respectively.

\section{Locating faulty $P V$ module in the high-voltage section}

If all the PV strings are faulty, the eigenvalues of Tables III$\mathrm{V}$ may be the same as other faulty conditions. This can lead to misjudgment in locating faulty modules.

For example, two types of the unhealthy $3 \times 3 \mathrm{PV}$ array with the same sensor placement strategy are presented in Fig. 8. PV11, PV21, PV23 and PV32 are faulty at fault condition 1; PV12, PV21, PV31 and PV33 are faulty at condition 2. Two fault conditions give the same voltage reading in the lowvoltage diagnosis section, which is $U_{\text {array }} / 2$. In order to discriminate the two conditions, the high voltage diagnosis section is employed to find the actual faulty modules. 
TABLE V VOLT OF THE MONO-STRING PARTIALLY FAULTED MODULES

\begin{tabular}{|c|c|c|c|c|}
\hline $\mathrm{PV}_{11} \sim \mathrm{PV}_{13}$ & $U_{\mathrm{a}}$ & $U_{\mathrm{b}}$ & $U_{\mathrm{c}}$ & Comparison \\
\hline 100 & $\begin{array}{c}U_{\text {array }} / 6<U_{\mathrm{a}}< \\
U_{\text {array }} / 3\end{array}$ & $U_{\text {array }} / 3$ & $\begin{array}{c}U_{\text {array }} / 3<U_{\mathrm{c}}< \\
2 U_{\text {array }} / 3\end{array}$ & - \\
\hline 010 & $\begin{array}{c}U_{\text {array }} / 6<U_{\mathrm{a}}< \\
U_{\text {array }} / 3\end{array}$ & $U_{\text {array }} / 3$ & $\begin{array}{c}U_{\text {array }} / 6<U_{\mathrm{c}}< \\
U_{\text {array }} / 3\end{array}$ & - \\
\hline 001 & $\begin{array}{c}U_{\text {array }} / 3<U_{\mathrm{a}}< \\
2 U_{\text {array }} / 3\end{array}$ & $U_{\text {array }} / 3$ & $\begin{array}{c}U_{\text {array }} / 6<U_{\mathrm{c}}< \\
U_{\text {array }} / 3\end{array}$ & - \\
\hline 110 & $U_{\mathrm{a}}<U_{\text {array }} / 3$ & $U_{\text {array }} / 3$ & $\begin{array}{c}U_{\text {array }} / 3<U_{\mathrm{c}}< \\
2 U_{\text {array }} / 3\end{array}$ & $2 U_{\mathrm{a}} \square U_{\mathrm{c}}<U_{\text {array }}$ \\
\hline 011 & $\begin{array}{c}U_{\text {array }} / 3<U_{\mathrm{a}}< \\
2 U_{\text {array }} / 3\end{array}$ & $U_{\text {array }} / 3$ & $U_{\mathrm{c}}<U_{\text {array }} / 3$ & $U_{\mathrm{a}} \square 2 U_{\mathrm{c}}<U_{\text {array }}$ \\
\hline 101 & $U_{\mathrm{a}}<U_{\text {array }} / 3$ & $U_{\text {array }} / 3$ & $\begin{array}{c}U_{\text {array }} / 3<U_{\mathrm{c}}< \\
2 U_{\text {array }} / 3 \\
\end{array}$ & $U_{\mathrm{a}} \square 2 U_{\mathrm{c}}>U_{\text {array }}$ \\
\hline
\end{tabular}

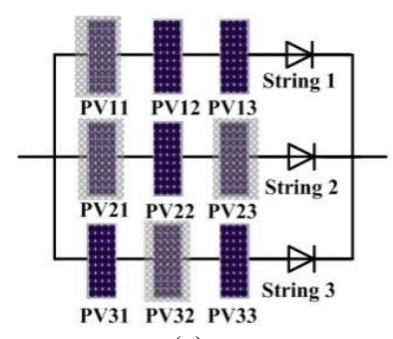

(a)

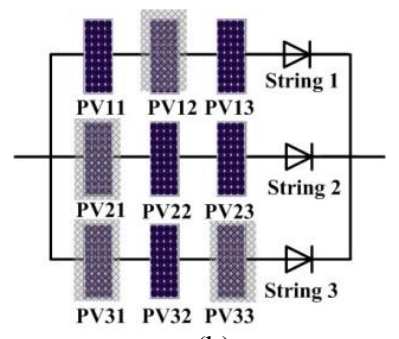

(b)
Fig. 8 The $3 \times 3$ array under two fault conditions: (a) 1, (b) 2 .

TABLE VI EIGENVALUE UNDER DIFFERENT FAULT DIAGNOSIS SECTIONS

\begin{tabular}{ccccc}
\hline Fault condition & Diagnosis section & $U_{\mathrm{a}}$ & $U_{\mathrm{b}}$ & $U_{\mathrm{c}}$ \\
\hline 1 & Low voltage & $U_{\text {array }} / 2$ & $U_{\text {array }} / 2$ & $U_{\text {array }} / 2$ \\
2 & Low voltage & $U_{\text {array }} / 2$ & $U_{\text {array }} / 2$ & $U_{\text {array }} / 2$ \\
1 & High voltage & $U_{\text {array }} / 2-U_{o c}$ & $2 U_{o c}-U_{\text {array }} / 2$ & $U_{\text {array }} / 2$ \\
2 & High voltage & $U_{\text {array }} / 2$ & $U_{\text {array }} / 2-U_{o c}$ & $2 U_{o c}-U_{\text {array }} / 2$ \\
\hline
\end{tabular}

As analyzed previously, when the PV array works in the high diagnosis voltage section, the faulty modules in string 2 are open-circuited while strings 1 and 3 can still operate. In a lowvoltage section all the healthy modules in the array generate electricity and the faulty modules are shorted. The voltage value is different between the low-voltage and the high voltage sections, as illustrated in Table VI. By changing the diagnosis section from low to high, different eigenvalues can be obtained to locate faulty modules.

\section{Implementation of the two-section fault diagnosis strategy}

The two-section fault diagnosis strategy is summarized in a flowchart in Fig. 9. Firstly, the system checks if the voltage sensor readings sufficiently deviate from the normal ones (e.g. $10 \%$ ). If this is true, the system enters into fault diagnosis. Next, the system checks if there is a healthy string in the PV array based on voltage sensor readings. If this is the case, the faulty module can be located directly by the eigenvalue table in the low-voltage diagnosis section. If there does not exist a healthy string, both the low-voltage and high-voltage fault diagnosis is needed to locate faulty modules.

\section{EXPERIMENTAL TESTS}

A $3 \times 3$ PV array and a signal conditioning system are built to verify the proposed fault diagnosis technique, as shown in Fig. 10. In this figure, resistor dividers are employed as differential voltage sensors to eliminate the grounding issue, triport connectors and shield twisted pair cables are used to transmit the voltage signal. In the signal conditioning circuit, the electrical isolation of sensor signals is achieved by using a linear optical coupling (HCNR201) to avoid the interaction of earth and ground connections. The voltage readings are

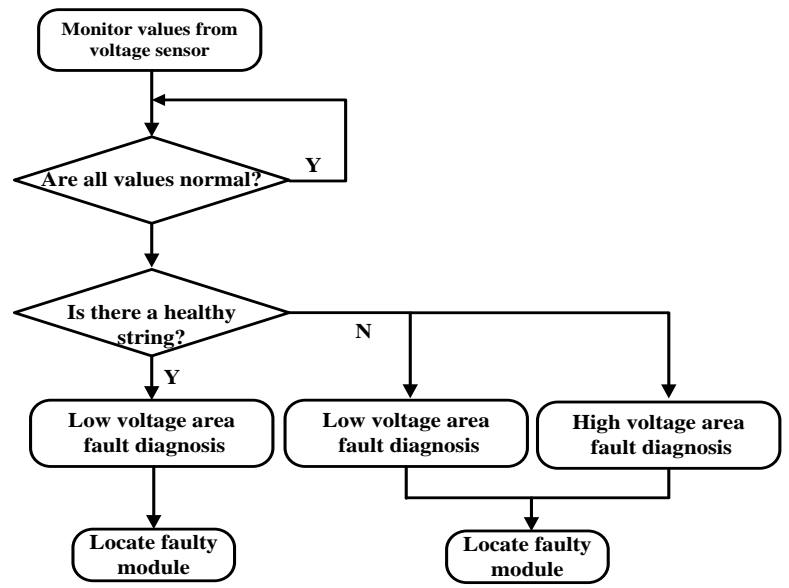

Fig. 9 Flowchart of the two-section fault diagnosis.

processed by the conditioning circuit and then input to DSP TMS320F2812. The PV modules are the same for simulation, and the environment illumination is recorded by TS1333R. In the experiment, typical fault scenarios are studied and the sensor readings are compared with eigenvalues in the highvoltage and low-voltage diagnosis sections to check the effectiveness of the proposed fault diagnosis technique.

Fig. 11 shows the mono-string mono-module fault diagnosis. In the fault scenario 1 (see Fig. 11(a)), the voltage sensor connection method is identical to that in Fig. 7. The illumination is $550 \mathrm{~W} / \mathrm{m}^{2}$ and the temperature is $15^{\circ} \mathrm{C}$. The $\mathrm{P} 33$ PV module is cast by shadow manually to emulate a partialshading fault. $U_{\text {aref }}, U_{\text {bref }}$ and $U_{\text {cref }}$ are the reference voltages for sensors $a, b$ and $c$, respectively, under the fault condition. Fig. 11(b) shows the I-V characteristics of faulty PV arrays. Due to the fault on module P33, string 3 cannot generate electricity in the output voltage range $82 \sim 120 \mathrm{~V}$. Fig. 11(c) presents the sensor output voltage. In the low-voltage diagnosis section $\left(10 \sim 70 \mathrm{~V}\right.$ ); the sensor $a$ output voltage is $U_{\text {array }} / 3$ (as shown in Fig. 11(d)). This is a normal output voltage and the corresponding strings are healthy. That is, strings 1 and 2 connected by this sensor are healthy, which coincides with fault scenario 1 in Fig. 11(a). Fig. 11(e) illustrates the high-voltage and low-voltage diagnosis sections. In the low-voltage section, the reference eigenvalue is $U_{\text {array }} / 6$; and in the high-voltage section, it is $2 U_{\text {array }} / 3-U_{o c}$. The fact that the sensor $b$ output is close to the reference value also verifies the proposed diagnosis method. The reference eigenvalue of $U_{c}$ is $2 U_{\text {array }} / 3$; and the corresponding sensor $c$ output also agrees with the reference eigenvalues. There is a slight deviation between $U_{a}, U_{b}$ and $U_{c}$ and their reference values. This is caused by the diode voltage drop and the minor product irregularity between PV modules. From the sensor output results and information in Table III, the fault type is classified as " 001 ". The faulty module is P33 that also agrees with fault scenario 1 (Fig. 11(a)).

Fig. 12 shows the diagnosis of the multi-string mono-module fault. In fault scenario 2, the illumination is $580 \mathrm{~W} / \mathrm{m}^{2}$ and the temperature is $25^{\circ} \mathrm{C}$. Module P11 in string 1 and P33 in string 3 are cast by partial shadow manually. Fig. 12(b) presents the I$\mathrm{V}$ characteristics of the faulty PV array. When faults occur in modules P11 and P33, strings 1 and 3 cannot generate electricity in the range of $82 \sim 120 \mathrm{~V}$. In the low-voltage section, the sensors $a$ and $b$ have the same output $\left(U_{a}=U_{b}=U_{\text {array }} / 6\right)$, as illustrated in Fig.12(c). The voltage sensors $a$ and $b$ also satisfy 
the rule for locating healthy strings. Therefore, string 2 is diagnosed as being healthy which coincides with the fault scenario in Fig. 12(a). Fig. 12(d) shows the sensor $c$ output curves. It can be seen that there is a healthy string, and the values of $U_{a}, U_{b}$ and $U_{c}$ are $U_{\text {array }} / 6, U_{\text {array }} / 6$ and $U_{\text {array }}$, respectively, in the low-voltage diagnosis section. The faulty modules identified are P11 and P33.

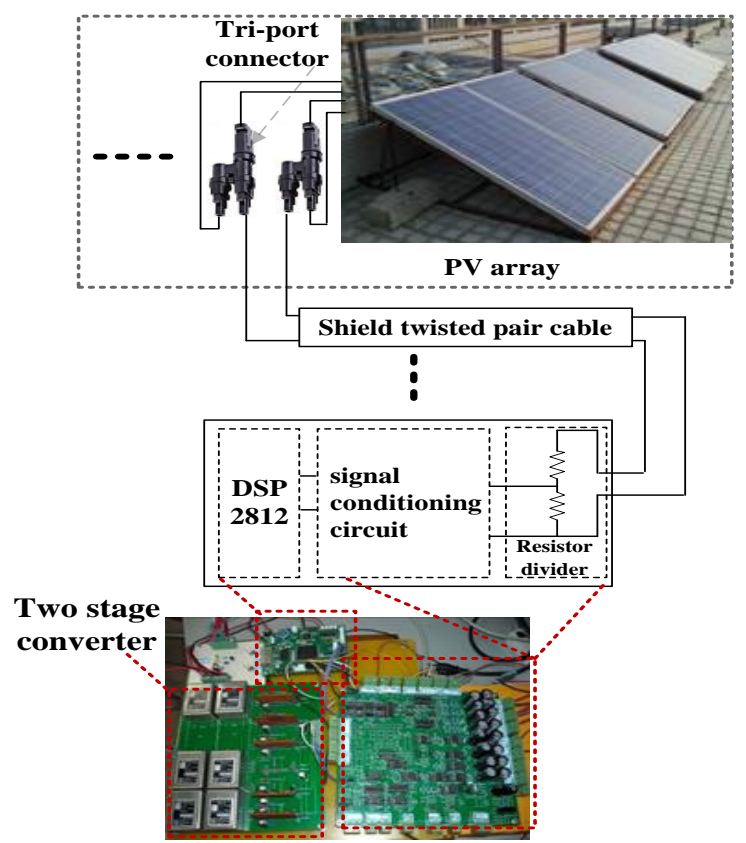

Fig. 10 Experimental platform.

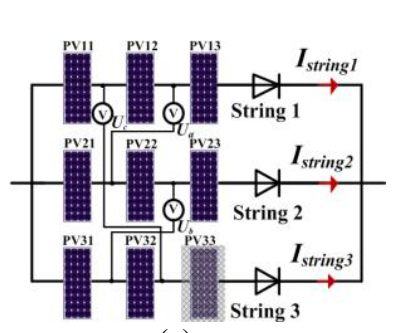

(a)

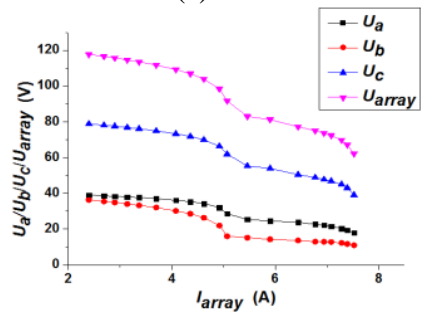

(c)

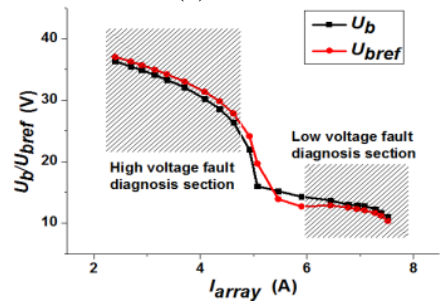

(e)

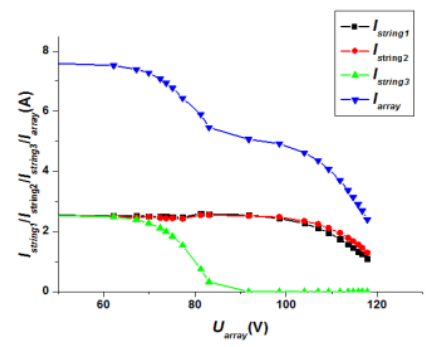

(b)

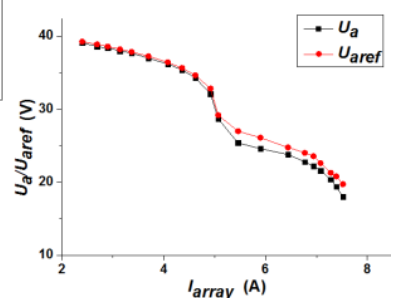

(d)

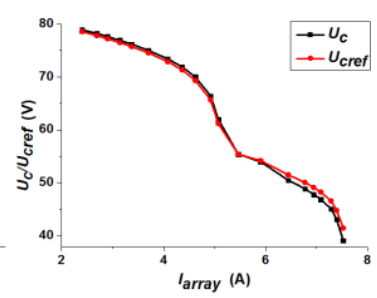

(f)
Fig. 11 Mono-string mono-module fully faulted diagnosis. (a) Fault scenario 1. (b) Output characteristics. (c) Voltage sensor output. (d) $U_{a}$ sensor output. (e) Comparison of $U_{b}$ sensor output. (f) Comparison of $U_{c}$ sensor output.

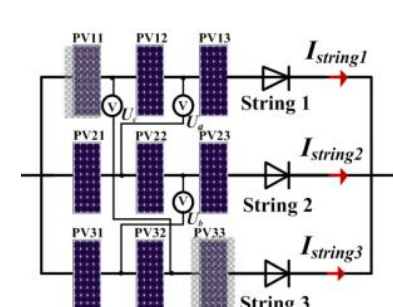

(a)

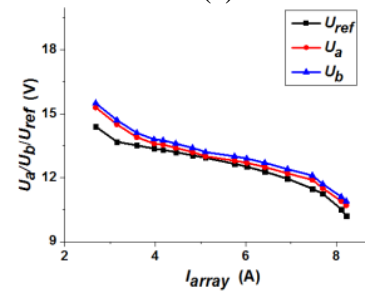

(c)

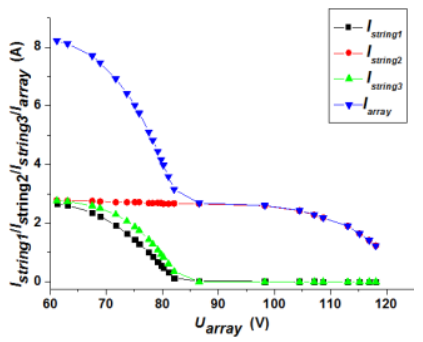

(b)

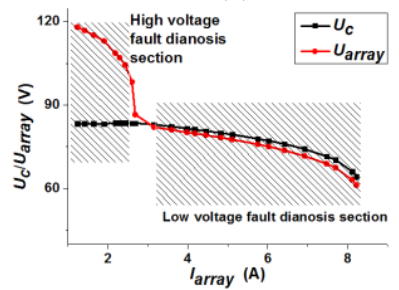

(d)
Fig. 12 Multi-string mono-module fault diagnosis. (a) Fault scenario 2. (b) Output characteristics. (c) Comparison of sensor outputs $U_{a}$ and $U_{b}$. (d) Sensor output voltage.

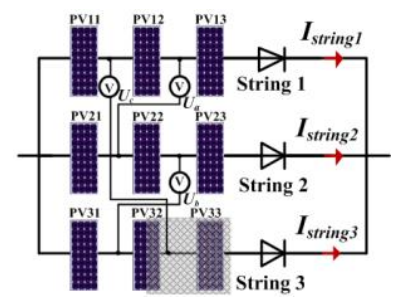

(a)

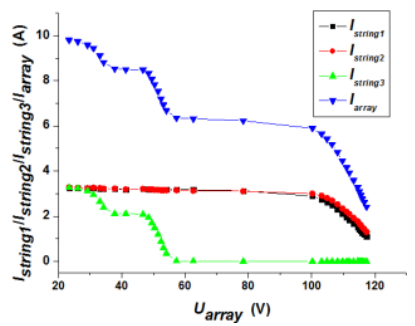

(b)

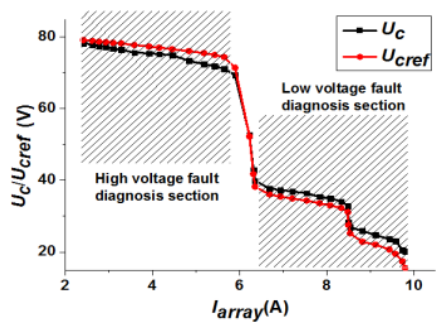

(d)

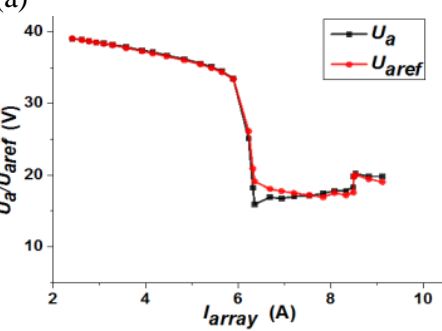

(c)

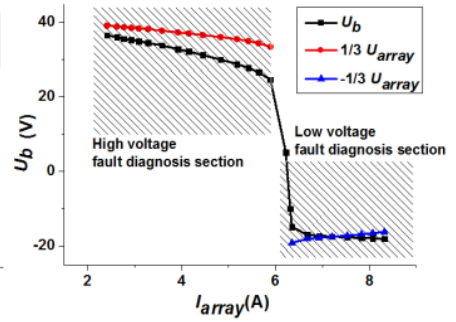

(e)
Fig. 13 Mono-string multi-module fault diagnosis. (a) Fault scenario 3. (b) Output characteristics. (c) $U_{a}$ sensor output. (d) Comparison of sensor output $U_{c}$. (e) Comparison of sensor output $U_{b}$.

In fault scenario 3 (Fig. 13(a)), the illumination is $610 \mathrm{~W} / \mathrm{m}^{2}$ at $30^{\circ} \mathrm{C} . \mathrm{P} 32$ and P33 in string 3 are cast by partial shadow and full shadow, respectively. Fig. 13(b) shows the output characteristics. String 3 can only generate electricity at $0 \sim 60 \mathrm{~V}$. As presented in Fig. 13(c), $U_{a}=U_{\text {array }} / 3$ in the whole output voltage range, indicating strings 1 and 2 are both healthy. In the low-voltage section of Fig. 13(d), $U_{c}$ matches the reference value $2 U_{\text {array }} / 3$, verifying that $\mathrm{P} 33$ is faulty. In the high-voltage section, $U_{c}=2 U_{o c}-U_{\text {array }} / 3$. Therefore, either P 31 or P 32 is faulty. Fig. 13(e) presents the output characteristics for sensor $b$. The 
corresponding output is equal to $-U_{\text {array }} / 3$ in the low-voltage range, proving that $\mathrm{P} 32$ module is faulty and $\mathrm{P} 31$ module is healthy.

From the analysis of three fault scenarios for a $3 \times 3 \mathrm{PV}$ array, the proposed fault diagnosis strategy is proven be effective.

For small-scale or low-voltage arrays, passive voltage sensors (e.g. resistor dividers) can be employed. Given that 16 channels are available for analog-digital (A/D) conversion in DSP TMS320F28335, there might not need for additional A/D chips. For large-scale PV systems at high voltages, Hall-effect voltage sensors (e.g. LEM LV25-P) are required. These sensors can be powered by the PV cell-unit directly. They also need long sensor cables to transmit the voltage results unless wireless sensor networks are used [38][39]. Clearly, the cost of the fault diagnosis equipment and computational complexity handling for more extended PV arrays and large PV arrays will be increased. Given the gain in reduced voltage sensors and increased solar power production, the total capital cost is justified by using the proposed technique.

It needs to point out that this is a proof-of-concept work and its technology readiness level (TRL) is between 3-4. Ideally, the developed technology will eventually lead to a new product, in place of existing converters for PV systems. However, it can also be integrated into the exiting commercial converters. i) If commercial converters allow for updating their software programs, the developed algorithm can be implemented into the control program of the front-end DC-DC converter and voltage sensors need to add to the system for voltage measurement. For fault diagnosis, the reference voltages of PV arrays in the lowvoltage and high-voltage fault diagnosis areas are firstly chosen. The difference between the PV array output voltage and the reference voltage is the input to the PI controller and its output is the duty cycle of the DC-DC converter. ii) If commercial converters do not allow any modification of their software programs, an extra DC-DC converter is needed and its output is connected across the DC-link capacitor. This arrangement bypasses the first stage of the commercial converter and fault diagnosis can be conducted when the PV system is operational.

\section{CONCLUSION}

PVs are a cost-sensitive market. Online fault diagnosis is key to the success of the PV array reconfiguration and the global MPPT. This paper has proposed a low-cost online PV array fault diagnosis with optimized voltage sensor locations. This work can increase productivity and reduce the capital and maintenance costs by reducing the number of sensors and by developing an effective fault diagnosis technique.

Compared to existing methods in the literature, this work has made the following improvements: i) String current sensors are removed and the number of voltage sensors is also reduced by optimizing the location of voltage sensors. ii) An online twosection fault diagnosis method is developed to locate faulty PV modules. iii) The state of health information from this work can be also used for the MPPT and PV array dynamical reconfiguration.

\section{REFERENCES}

[1] Y. A. Mahmoud, W. Xiao, H. H. Zeineldin, "A parameterization approach for enhancing PV model accuracy," IEEE Trans. Ind. Electron., vol. 60, no.12, pp. 5708-5716, 2013.

[2] B. N. Alajmi, K. H. Ahmed, S. J. Finney, B. W. Williams, "A maximum power point tracking technique for partially shaded photovoltaic systems in microgrids," IEEE Trans. Ind. Electron., vol. 60, no. 4, pp. 1596-1606, April 2013.

[3] L. Gao, R. A. Dougal, S. Liu, and A. P. Iotova, "Parallel-connected solar PV System to address partial and rapidly fluctuating shadow conditions," IEEE Trans. Ind. Electron., vol. 56, no. 5, pp. 1548-1556, May 2009.

[4] N Femia, G Petrone, G Spagnuolo, M Vitelli," A technique for improving P\&O MPPT performances of double-stage grid-connected photovoltaic systems," IEEE Trans. Ind. Electron., vol. 56, no. 11, pp. 4473-4482, Nov. 2009.

[5] K. Ishaque, and Z. Salam, "A deterministic particle swarm optimization maximum power point tracker for photovoltaic system under partial shading condition," IEEE Trans. Ind. Electron., vol. 60, no. 8, pp. 3195 3206, Aug. 2013.

[6] M. Boztepe, F. Guinjoan, G. Velasco-Quesada, S. Silvestre, A. Chouder, E. Karatepe, "Global MPPT scheme for photovoltaic string inverters based on restricted voltage window search algorithm," IEEE Trans. Ind. Electron., vol. 61, no. 7, pp. 3302-3312, Jul. 2014.

[7] K. Ding, X. Bian, H. Liu, T. Peng, "A MATLAB-Simulink-based PV module model and its application under conditions of nonuniform irradiance," IEEE Trans. Energy Convers., vol. 27, no. 4, pp. 864-872, Dec. 2012.

[8] G Petrone, G Spagnuolo, M Vitelli, "Analytical model of mismatched photovoltaic fields by means of Lambert W-function," Solar Energy Materials and Solar Cells, vol. 91 no. 18, pp. 1652-1657, Nov. 2007.

[9] Y. Hu, Y. Deng, Q. Liu, X. He, “Asymmetry three-level grid-connected current hysteresis control with varying bus voltage and virtual over-sample method," IEEE Trans. Power Electron., vol. 29, no. 6, pp. 3214-3222, Jun. 2014.

[10] Y. Liu, B. Ge, H. Abu-Rub, and F. Z. Peng, "An effective control method for three-phase quasi-Z-source cascaded multilevel inverter based grid-tie photovoltaic power system," IEEE Trans. Ind. Electron., vol. 61, no. 12, pp. 6794-6802, Dec. 2014.

[11] S. Djordjevic, D. Parlevliet, P. Jennings, "Detectable faults on recently installed solar modules in Western Australia" Renewable Energy, vol. 67, pp. 215-221, 2014.

[12] A. Maki, S. Valkealahti, "Effect of photovoltaic generator components on the number of MPPs under partial shading conditions," IEEE Trans. Energy Convers., vol. 28, Issue 4, pp.1008-1017, 2013.

[13] M. Z. S El-Dein, M. Kazerani, M. M. A. Salama, "Optimal photovoltaic array reconfiguration to reduce partial shading losses," IEEE Trans. Sustain. Energy, vol. 4, Issue 1, pp. 145-153, 2013.

[14] E. V. Paraskevadaki, S. A. Papathanassiou, "Evaluation of MPP voltage and power of mc-Si PV modules in partial shading conditions," IEEE Trans. Energy Convers., vol. 26, Issue 3, pp. 923-932, 2011.

[15] H. A. Lauffenburger, R. T. Anderson, "Reliability terminology and formulae for photovoltaic power systems," IEEE Trans. Rel., vol. R-31, Issue 3, pp. 289-295, 1982.

[16] L. H. Stember, W. R. Huss, M. S. Bridgman, "A methodology for photovoltaic system reliability \& economic analysis," IEEE Trans. Rel., vol. R-31, Issue 3, pp. 296-303, 1982.

[17] C. Buerhopa, D. Schlegela, M. Niessb, C. Vodermayerb, R. Weißmanna, C. J. Brabeca, "Reliability of IR-imaging of PV-plants under operating conditions," Solar Energy Materials and Solar Cells, vol. 107, pp. 154164, 2012.

[18] Y. Hu, B. Gao, G.Y. Tian, X. Song, K. Li, X. He. "Photovoltaic fault detection using a parameter based model," Solar Energy, vol. 96, pp. 96102, Oct. 2013.

[19] A. Krenzinger, A. C. Andrade, "Accurate outdoor glass thermographic thermometry applied to solar energy devices," Solar Energy, vol. 81, pp. 1025-1034, 2007.

[20] M. Simon and E. L. Meyer, "Detection and analysis of hot-spot formation in solar cells," Solar Energy Materials and Solar Cells, vol. 94, no. 2, pp. 106-113, 2010.

[21] J. Kurnik, M. Jankovec, K. Brecl and M. Topic, "Outdoor testing of PV module temperature and performance under different mounting and operational conditions," Solar Energy Materials \& Solar Cells, vol. 95, pp. 373-376, 2011.

[22] Y. Hu, W. Cao, J. Wu, B. Ji, D. Holliday, "Thermography-based virtual MPPT scheme for improving PV energy efficiency at partial shading 
conditions," IEEE Trans. Power Electron. vol. 29, no. 11, pp. 5667-5672, Jun. 2014.

[23] Z. Zou, Y. Hu, B. Gao, W. L.Woo and X. Zhao, "Study of the gradual change phenomenon in the infrared image when monitoring photovoltaic array," Journal of Applied Physics, vol. 115, no. 4, pp. 1-11, 2014.

[24] T. Takashima, J. Yamaguchi, K. Otani, T. Oozeki, K. Kato, "Experimental studies of fault location in PV module strings," Solar Energy Materials and Solar Cells, vol. 93 issues. 6-7, pp. 1079-1082, Jun. 2009.

[25] R. A. Kumar, M. S. Suresh, J. Nagaraju, "Measurement of AC parameters of gallium arsenide (GaAs/Ge) solar cell by impedance spectroscopy," IEEE Trans. Electron Devices, vol. 48, issue 9, pp. 2177-2179, 2001.

[26] A. Chouder, S. Silvestre, "Automatic supervision and fault detection of PV systems based on power losses analysis," Energy Conversion and Management, vol. 51, issue 10, pp. 1929-1937, Oct. 2010.

[27] S. Silvestre, A. Chouder, E. Karatepe, "Automatic fault detection in grid connected PV systems," Solar Energy, vol. 94, pp. 119-127, Aug. 2013.

[28] N. Gokmen, E. Karatepe, S. Silvestre, B. Celik, P. Ortega, "An efficient fault diagnosis method for PV systems based on operating voltagewindow," Energy Conversion and Management, vol. 73, pp. 350-360, Sep. 2013

[29] X. Lin, Y. Wang, D. Zhu, N. Chang and M. Pedram, "Online fault detection and tolerance for photovoltaic energy harvesting systems," the 2012 IEEE/ACM International Conference on Computer-Aided Design (ICCAD), San Jose, USA, pp. 1-6. 2012.

[30] D. Nguyen, B. Lehman. "An adaptive solar photovoltaic array using model-based reconfiguration algorithm," IEEE Trans. Ind. Electron., vol. 55, no. 7, pp. 2644-2654, Jul. 2008.

[31] J. P. Storey, P. R. Wilson, and D. Bagnall, "Improved optimization strategy for irradiance equalization in dynamic photovoltaic arrays," IEEE Trans. Power Electron., vol. 28, no. 6, pp. 2946-2956, Jun. 2013.

[32] G. Velasco-Quesada, F. Guinjoan-Gispert, R. Pique-Lopez, M. RomanLumbreras, and A. Conesa-Roca, "Electrical PV array reconfiguration strategy for energy extraction improvement in grid-connected PV systems," IEEE Trans. Ind. Electron., vol. 56, no. 11, pp. 4319-4331, Nov. 2009

[33] Y. Wang, X. Lin, Y. Kim, N. Chang, and M. Pedram, "Architecture and control algorithms for combating partial shading in photovoltaic systems," IEEE Trans. Comput.-Aided Design Integr. Circuits Syst., vol. 33, no. 6, pp. 917-929, Jun. 2014.

[34] S. Jonathan, R. W. Peter, and B. Darren, "The optimized-string dynamic photovoltaic array," IEEE Trans. Power Electron., vol. 29, no. 4, pp. 1768 1776, Apr. 2014

[35] P. L. Carotenuto, P. Manganiello, G. Petrone, and G. Spagnuolo, "Online recording a PV module fingerprint," IEEE J. Photovolt, vol. 4, no. 2, pp. 659-668, Mar. 2014.

[36] Y. Hu, H. Chen, R. Xu, R. Li. "Photovoltaic (PV) array fault diagnosis strategy based on optimal sensor placement," Proceedings of the CSEE, vol. 31, issue 33, pp. 19-30, 2011

[37] B. Yang, W. Li, Y. Zhao and X. He, "Design and analysis of a gridconnected photovoltaic power system," IEEE Trans. Power Electron., vol. 25, no. 4, pp. 992-1000, Apr. 2010.

[38] P. Guerriero, V. d'Alessandro, L. Petrazzuoli, G. Vallone, and S. Daliento, "Effective real-time performance monitoring and diagnostics of individual panels in PV plants," the 4th International Conference on Clear Electrical Power (ICCEP), Alghero, Italy, pp. 14-19. 2013.

[39] P. Guerriero, G. Vallone, M. Primato, F. Di Napoli, L. Di Nardo, V. d'Alessandro, S. Daliento, "A wireless sensor network for the monitoring of large PV plants," the International Symposium on Power Electronics, Electrical Drives, Automation and Motion (SPEEDAM), Ischia, Italy, pp. 960-965, 2014

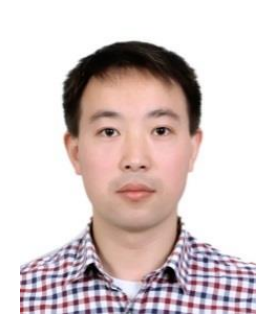

Yihua Hu (M'13) received the B.Sc. in electrical motor drives in 2003, and the Ph.D. in power electronics and drives in 2011, both from China University of Mining and Technology, Jiangsu, China. Between 2011 and 2013, he was with the College of Electrical Engineering, Zhejiang University as a Postdoctoral Fellow. Between November 2012 and February 2013, he was an academic Visiting Scholar with the School of Electrical and Electronic Engineering, Newcastle University, Newcastle upon Tyne, UK. He is currently a Research Associate with the Department of Electronic \& Electrical Engineering, University of Strathclyde, Glasgow, U.K. His research interests include PV systems, DC-DC/DC-AC converters, and electrical motor drives.

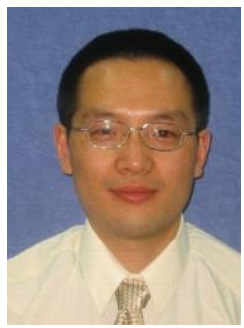

Jiangfeng Zhang obtained his $\mathrm{BSc}$ and $\mathrm{PhD}$ in computing mathematics and applied software from Xi'an Jiaotong University, China, in July 1995 and December 1999, respectively. He is a senior lecturer at the Department of Electronic and Electrical Engineering, University of Strathclyde, Glasgow, U.K. $\mathrm{He}$ is also a member of the IFAC TC6.3 (Power and Energy Systems). His research interests include modeling and control of energy systems, with a focus on energy efficiency and demand side management.

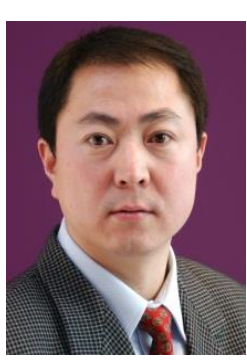

Wenping Cao (M'05-SM'11) received the B.Eng in electrical engineering from Beijing Jiaotong University, Beijing, China, in 1991, and the Ph.D. degree in electrical machines and drives from the University of Nottingham, Nottingham, U.K., in 2004.

$\mathrm{He}$ is currently a Marie Curie Fellow with the Massachusetts Institute of Technology, Cambridge, MA, U.S.A, and a Senior Lecturer with Queen's University Belfast, Belfast, U.K. Dr. Cao received the "Best Paper Award" at the LDIA'13 Conference, the "Innovator of the Year" Award from Newcastle University in 2013, and was the Winner of the "Dragons' Den Competition" at Queen's University Belfast in 2014. He serves as an Associate Editor for IEEE TRANSACTIONS ON INDUSTRY APPLICATIONS, IEEE INDUSTRY APPLICATIONS MAGAZINE and IET Power Electronics, the Chief Editor for two Special Issues, an Editor for Electric Power Components \& Systems Journal and nine other International Journals. His research interests are in fault analysis and condition monitoring of electric machines and power electronics.

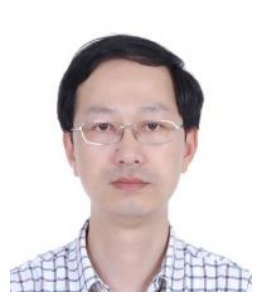

Jiande Wu (M'11) received the B.Sc. and the Ph.D. in power electronics from Zhejiang University in 1994 and 2012, respectively. He has been a faculty member at Zhejiang University since 1997 and is currently an associate professor. From Oct. 2013 to Oct. 2014, he was an academic visitor at the University of Strathclyde, Glasgow, U.K. His research interests include applications of power electronics and network communication.

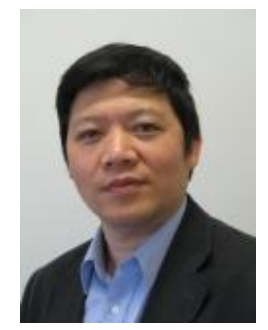

Gui Yun Tian (M'01-SM'03) received the B.Sc. in metrology and instrumentation and the M.Sc. in precision engineering from the University of Sichuan, Chengdu, China, in 1985 and 1988, respectively, and the Ph.D. degree from the University of Derby, Derby, U.K., in 1998. He is currently a Chair Professor in sensor technologies at Newcastle University, Newcastle upon Tyne, U.K. He is also with the School of Automation Engineering, University of Electronic Science and Technology of China, Chengdu, China. He has coordinated several research projects from the Engineering and Physical Sciences Research Council, Royal Academy of Engineering and FP7. He also has collaborative links with leading industrial companies, such as Airbus, Rolls Royce, BP, nPower, and TWI.

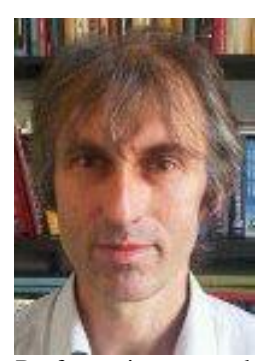

Stephen J. Finney obtained the M.Eng in electrical and electronic engineering from Loughborough University of Technology in 1988; and the Ph.D. degree from Heriot-Watt University, Edinburgh, U.K., in 1995. He worked for the Electricity Council Research Centre before joining the Power Electronics Research Group at Heriot-Watt University in 1990. From 1994 to 2005 he was a member of academic staff at Heriot-Watt University. Since 2005 he is with the Institute of Energy and Environment, University of Strathclyde, Glasgow, U.K., where he is currently a Professor in power electronic systems. His research interests include the power electronics for high power applications, power transmission and distribution. 


\section{IEEE TRANSACTIONS ON INDUSTRIAL ELECTRONICS}

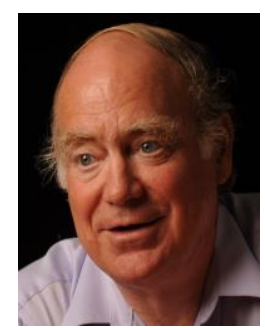

James L. Kirtley Jr. (LF'91) is a Professor of electrical engineering at the Massachusetts Institute of Technology, Cambridge, MA, U.S.A. He was with General Electric, Large Steam Turbine Generator Department as an Electrical Engineer, and with Satcon Technology Corporation as Vice President and General Manager of the Tech Center, and Chief Scientist and Director.

Dr. Kirtley attended MIT as an undergraduate and received the Ph.D. from MIT in 1971. He was Gastdozent at the Swiss Federal Institute of Technology, Switzerland. He served as Editor in Chief of the IEEE TRANSACTIONS ON ENERGY CONVERSION from 1998 to 2006 and continues to serve as Editor for that journal, and as a member of the Editorial Board of the Electric Power Components \& Systems Journal. He was awarded the IEEE Third Millennium medal in 2000, and the Nikola Tesla prize in 2002. He was elected to the United States National Academy of Engineering in 2007. His research interests are electric machinery and electric power systems. 